BIOMEDICAL AND BIOSOCIAL ANTHROPOLOGY
$\begin{gathered}\text { Official Journal of the International Academy } \\ \text { of Integrative Anthropology } \\ \text { journal homepage: http://bba-journal.com }\end{gathered}$

\title{
Evaluation of the effectiveness of early intervention methods in newborns who have suffered hypoxic-ischemic CNS damage
}

Halactionova I. V. ${ }^{1}$ Iziumets O. I. ${ }^{2}$, Korolova N. D. ${ }^{2}$, Zhuk K. V. ${ }^{2}$, Angelska V. Y. ${ }^{2}$

${ }^{1}$ Vinnytsia Regional Children's Clinical Hospital, Vinnytsia, Ukraine

${ }^{2}$ National Pirogov Memorial Medical University, Vinnytsya, Ukraine

\section{ARTICLE INFO}

Received: 16 October 2020

Accepted: 18 November 2020

UDC: $616.831-005.4-053.31: 611.81$

\section{CORRESPONDING AUTHOR}

e-mail: galactina29@gmail.com Halactionova I. V.
Timely diagnosis of cerebral disorders both in the prenatal period and in the early neonatal period, as well as early rehabilitation treatment is the basis for the prevention of childhood disability. To this end, the so-called Early Intervention System is being introduced in Ukraine. The effectiveness of early intervention techniques directly depends on timely diagnosis and correctly chosen intervention tactics. Given the high neuroplasticity of the developing brain, it is advisable to start the elements of neurodevelopmental therapy from infancy. The aim of the work is to evaluate the effectiveness of methods of early intervention in children of the first 3 months of life who have suffered hypoxic-ischemic CNS damage in the neonatal period, by assessing the main indicators of psycho-motor development. 101 children who were treated in the neonatal pathology department due to hypoxic-ischemic CNS damage and did not have concomitant somatic pathology were examined. The children were in the ward for rehabilitation. To assess the effectiveness of comprehensive rehabilitation in young children, it is advisable to use adapted for Ukraine scale of Munich functional developmental diagnostics, which allows to assess the child's development in all major areas, its harmony and effectiveness of rehabilitation measures during the first 3 years of life. Statistical processing of the obtained results should be performed in the license package "Statistica 6.1 for Windows". Timely diagnosis of cerebral disorders both in the prenatal period and in the early neonatal period, as well as early rehabilitation treatment is the basis for the prevention of childhood disability. Given the high neuroplasticity of the developing brain, it is advisable to start the elements of neurodevelopmental therapy from infancy. The effectiveness of the methods recommended for use depends on timely diagnosis and correctly chosen intervention tactics. Assessment of the effectiveness of care for children at risk of deviant psychomotor development should be based on the application of the criteria and scales recommended by international expert groups, which are adapted in our country. Signs of full-fledged early intervention in the region are: perinatal diagnosis of congenital pathology, timely provision of medical and rehabilitation, social and special pedagogical services to children aged 0 to 3 years and their families. In order to achieve the set goals, in our opinion, the priority measures should be steps to implement the national protocol for care for children with perinatal CNS injuries, approval and implementation in Ukraine of the modern International Classification of Functioning, Life and Health Restrictions, providing medical care, rehabilitation and social services for young children.

Keywords: early intervention, newborns, hypoxic-ischemic encephalopathy, assessment of psychomotor development, rehabilitation of young children, effectiveness.

\section{Introduction}

Unfavorable onset of life in the neonatal period can cause a variety of health problems, ranging from moderate developmental delays to severe disabling diseases, which in turn leads to problems with adaptation in society in adulthood [9, 28]. According to international experts, in the future the annual income of persons who had adverse circumstances at birth will be 1/4 lower than the average, which is 2 times higher than the cost of their early 
rehabilitation and education [24]. Scientific data show that early childhood is not only a period of special sensitivity to various risk factors, but also an important period in life, when a set of therapeutic measures gives a double return, and the negative effect of risk factors is mitigated [28]. The positive effect of comprehensive care for the child in the first years of life will be manifested in the future in the form of better health, well-being, higher learning ability and higher income. Services and measures to maintain the health of young children are an important condition for preserving the potential of each individual throughout his life and the potential of the generation as a whole [9].

The incidence of the nervous system, which leads to disability and maladaptation of children, in $70-80 \%$ of cases due to perinatal factors. Among the factors affecting children in the perinatal period, hypoxia is one of the most common $[1,4,5]$. In essence, hypoxic-ischemic encephalopathy (HIE) is a post-stroke encephalopathy $[1,5,16]$. HIE is a term used to describe a set of complex physiological, cellular and molecular changes that occur due to impaired oxygen supply to the brain [8]. HIE causes severe lifelong morbidity, including cerebral palsy and premature mortality [4, 19]. According to Barashnev Y. I. [3], timely diagnosis of cerebral disorders both in the prenatal period and in the early neonatal period, as well as early rehabilitation treatment is the basis for the prevention of childhood disability.

To this end, the so-called Early Intervention System is being introduced in Ukraine. Early intervention - all types of activities aimed at child development and parental support, which are carried out immediately and immediately after determining the status and level of development of the child (European Organization for Early Intervention, 1993) [10, 28]. The Early intervention program was first developed in the United States and Western Europe for children in their first 3 years of life. Its purpose is to detect deviations in the child's development as early as possible and provide appropriate assistance to the child and his family [2]. Early intervention is aimed at developing all the basic skills of the child. These include motor development, cognitive and communication skills, self-care and the development of the socio-emotional sphere. The philosophy of early intervention is based on the focus on the family in which the child lives, the priority of the child's interests, respect for its problems, taking into account the circumstances of life and family values $[9,13]$.

There are no official statistics on the number of children in need of early intervention in Ukraine. The experience of developed countries shows that $13-18 \%$ of children in the first 3 years of life have developmental disabilities and need qualified care [28]. In Ukraine, to assess the adequacy of motor development of the child, health workers are guided by the order of the Ministry of Health № 149 "Clinical protocol of medical care for a healthy child under 3 years" from 2008 [21]. The international assessment of the state of assistance to children also indicates the need to further improve the provision of assistance to children with disabilities (recommendations of the UN Committee on the Rights of the Child 2011 and 2014) [10]. The development of the Concept of Social Pediatrics in Ukraine (Resolution of the Committee of the Verkhovna Rada of January 13, 2015 № 96-VIII) is a logical consequence of these recommendations [20]. Priority areas, according to this Concept are: prevention of disabling pathology in children; formation of a single rehabilitation space around the child and his family by forming a single system of rehabilitation institutions at different levels.

Rehabilitation of children with organic damage to the nervous system aims to prevent or reduce the effects of organic damage to the CNS and improve the social integration of the child. To achieve this goal, it is advisable to involve in the process of diagnosis and recovery of the child a multidisciplinary team of specialists, in particular, a neonatologist, neurologist, medical psychologist, ophthalmologist, orthopedist and physical therapist [20, 22]. The main provisions of specialized care for children are reflected in the "Unified clinical protocol of primary, secondary (specialized) and tertiary (highly specialized) medical care and medical rehabilitation of children with movement disorders" [22].

To work with newborns and young children, it is advisable to use a comprehensive approach to neurorehabilitation. An individual rehabilitation program is developed for each child depending on its needs and capabilities [3,6]. A prerequisite is a comprehensive examination of the child to determine the nature and extent of brain damage, determine the functional state of the child, the presence of concomitant somatic pathology and associated disorders in order to plan further individual rehabilitation program $[6,15,21]$.

In perinatal neurology, the combinations of the author's neurodeveloping methods and techniques of classical massage and therapeutic physical training are generally accepted. Neurodevelopmental therapy (NDT), aimed at suppressing the activity of pathological tonic reflexes, translational reactions and motor stereotypes with the subsequent restoration of statics and motor skills [17, 18]. To achieve optimal sensory-motor and intellectual development, it is recommended to combine methods of physical impact with the so-called sensory integration of the child, ie to influence different areas of perception (sight, hearing, touch) for better adaptation of the child in the environment [20, 22].

The aim of the work is to evaluate the effectiveness of methods of early intervention in children of the first 3 months of life who have suffered hypoxic-ischemic CNS damage in the neonatal period, by assessing the main indicators of psycho-motor development.

\section{Materials and methods}

For the purpose of the greatest efficiency of carrying out methods of early intervention it is expedient to carry out diagnostics of the psychoneurological status of the child 
with the use of valid scales before the beginning of procedures. The vast majority of methods for assessing the neurological status of the newborn are aimed at determining the level of consciousness $[6,20]$ or assessing the motor area [20,22]. At the same time, insufficient attention is paid to psycho-emotional and pre-speech development, which does not give a complete picture of the child's neurological status and possible prognosis. After reaching the 1st year, the range of diagnostic capabilities is significantly expanded [17, 26]. Currently, the Munich Functional Diagnosis of Development (MFDD) meets the requirements for the assessment of children from birth to 3 years of age $[6,7]$. This technique is aimed at early diagnosis of abnormalities in the development of the child for a special correction of the identified pathological changes. First of all, the method assesses the level of development of the motor functional system. However, it is possible to assess the state of perceptual, cognitive, linguistic functional systems and the state of social interaction. The diagnostic scale determines the degree of maturity of individual functional brain systems according to the concept of developmental neurology. The results of the Munich diagnostic determine the degree of compliance of the child's development with his passport age, as well as his psychophysical age, which is a unique criterion that gives an objective assessment of corrective measures. In children with organic lesions of the nervous system, according to the Munich Diagnosis of Development, functional systems develop unevenly, which disrupts their interaction [7]. The results of the examination with the help of MFDD, along with a clinical neurological examination, become the basis for the development of an individual rehabilitation program for a specific child with organic damage to the nervous system $[6,10]$.

Test card for assessing the physical and neuropsychological development of a child in the first year of life according to the protocol of the Munich Functional Diagnosis of Child Development is used to test and determine the psychological age of a child in the first year of life on scales: crawling, sitting, leaning, grasping, perception, expressive speech, language comprehension, social age. The function of language comprehension is assessed from the 10th month of life $[11,20]$. The test card for assessing the physical and neuropsychological development of a child 2-3 years of age contains assessment scales for the age of uprightness, age of fine motor skills, perception (understanding of relationships), age of active speech, language comprehension and social age. The presence or absence of the skill is assessed at the age when it is acquired by $95 \%$ of children with a normal rate of development. Both cards are interconnected, which allows you to monitor the development of each child from birth to 3 years. This, in turn, allows professionals at different stages of helping children to understand the degree of development and dynamics of the formation of individual skills and the general level of development of the child, avoiding subjective judgments.

101 children who were treated in the neonatal pathology department of the Children's Regional Clinical Hospital due to hypoxic-ischemic CNS damage and did not have concomitant somatic pathology were examined. The children were in the ward for rehabilitation treatment at the age of 1 to 3 months. The course of early rehabilitation was determined by the pediatric neurologist individually and contained elements of neurodevelopmental therapy, selected according to age, general and local massage, physical therapy and elements of sensory integration. The main criteria in the choice of early intervention procedures were the main national and international recommendations $[20,22,27]$.

To assess the effectiveness of rehabilitation in children in the first 3 months of life, the scale was adapted to the appropriate age. The presence of each skill was evaluated in 1 point, and the absence - 0 points, respectively. Thus, the skill "Crawling" according to MFDD can be assessed from 0 to 4 points at the end of the 1 st month of life. At 3 months, the child can acquire 2 more skills related to the development of crawling, ie the maximum can be estimated at 6 points. The "Seat" function in the first month of a child's life can have a range of 0-4 points, and at the end of the 2 nd from 0 to 5 points, respectively. Thus, the child's skills are calculated for each of the categories.

To perform statistical processing of the results obtained during the work, a licensed standard package of multidimensional statistical analysis applications "Statistica 6.1 for Windows" (intellectual property of the Center for New Information Technologies of National Pirogov Memorial Medical University, Vinnytsya, licensed № BXXR901E245722FA) was used.

\section{Results}

The first group consisted of 48 children who suffered from encephalopathy of hypoxic-ischemic origin of moderate and severe degree and after withdrawal from the acute period, in addition to drug therapy according to the protocol received a course of early rehabilitation in the form of neurodevelopmental therapy and correctional massage with elements. In addition, an appropriate sensory background was created for each child in order to avoid excessive light, sound and sensory stimuli. Children

Table 1. The main indicators of physical development of children in the study groups $(\mathrm{M} \pm \mathrm{m})$.

\begin{tabular}{|l|c|c|c|}
\hline \multicolumn{1}{|c|}{ Indicators } & 1 group $(\mathrm{n}=48)$ & 2 group $(\mathrm{n}=53)$ & $\mathrm{p}$ \\
\hline Body weight at birth $(\mathrm{g})$ & $3105 \pm 182$ & $3040 \pm 160$ & $>0.05$ \\
\hline Gestational age (weeks) & $37.33 \pm 2.81$ & $38.7 \pm 1.45$ & $>0.05$ \\
\hline Full-term (\%) & $75.01 \pm 6.25$ & $71.73 \pm 6.17$ & $>0.05$ \\
\hline Apgar score 1min. (points) & $2.732 \pm 0.13$ & $2.661 \pm 0.105$ & $>0.05$ \\
\hline Apgar score 5min. (points) & $5.068 \pm 0.143$ & $5.983 \pm 0.062$ & $<0.001$ \\
\hline
\end{tabular}

Notes: $p$ - the reliability of the differences between the 1st and 2nd groups. 
Table 2. Indicators of psychomotor development of children of the studied groups at the beginning (1st month) and at the end (3rd month) of the recovery period $(\mathrm{M} \pm \mathrm{m})$.

\begin{tabular}{|c|c|c|c|c|c|c|c|c|}
\hline \multirow{2}{*}{ Indicators } & \multicolumn{2}{|c|}{1 group $(n=48)$} & \multirow[b]{2}{*}{$\mathrm{p}$} & \multicolumn{2}{|c|}{2 group $(n=53)$} & \multirow{2}{*}{$\mathrm{p}$} & \multirow{2}{*}{$\mathrm{p}_{1}$} & \multirow{2}{*}{$\mathrm{p}_{2}$} \\
\hline & 1 month & 3 month & & 1 month & 3 month & & & \\
\hline Crawling & $1.854 \pm 0.89$ & $3.271 \pm 1.003$ & $>0.05$ & $1.962 \pm 1.107$ & $2.415 \pm 1.083$ & $>0.05$ & $>0.05$ & $>0.05$ \\
\hline Sitting & $1,354 \pm 0,731$ & $2.875 \pm 0.850$ & $=0.090$ & $1.603 \pm 0.936$ & $2.188 \pm 0.984$ & $>0.05$ & $>0.05$ & $>0.05$ \\
\hline Walking & $1.020 \pm 0.532$ & $2.166 \pm 0.661$ & $=0.090$ & $1.113 \pm 0.601$ & $1.452 \pm 0.753$ & $>0.05$ & $>0.05$ & $>0.05$ \\
\hline Grasping & $1.354 \pm 0.782$ & $2.250 \pm 0.621$ & $>0.05$ & $1.622 \pm 0.851$ & $1.924 \pm 0.772$ & $>0.05$ & $>0.05$ & $>0.05$ \\
\hline Expressive speech & $1.312 \pm 0.683$ & $2.354 \pm 0.775$ & $>0.05$ & $1.433 \pm 0.680$ & $1.867 \pm 0.705$ & $>0.05$ & $>0.05$ & $>0.05$ \\
\hline Social age & $1.229 \pm 0.615$ & $2.104 \pm 0.562$ & $>0.05$ & $1.207 \pm 0.627$ & $1.641 \pm 0.726$ & $>0.05$ & $>0.05$ & $>0.05$ \\
\hline Age of perception & $0.875 \pm 0.541$ & $2.229 \pm 0.763$ & $=0.070$ & $1.056 \pm 0.662$ & $1.792 \pm 0.918$ & $>0.05$ & $>0.05$ & $>0.05$ \\
\hline
\end{tabular}

Notes: $p$ - the significance of differences between 1 and 3 months in the 1st or 2nd groups; $p_{1}$ - the reliability of the differences in the indicators of the 1 st month between the 1 st and $2 n d$ groups; $p_{2}$ - significance of differences in the indicators of the 3rd month between the 1st and 2nd groups.

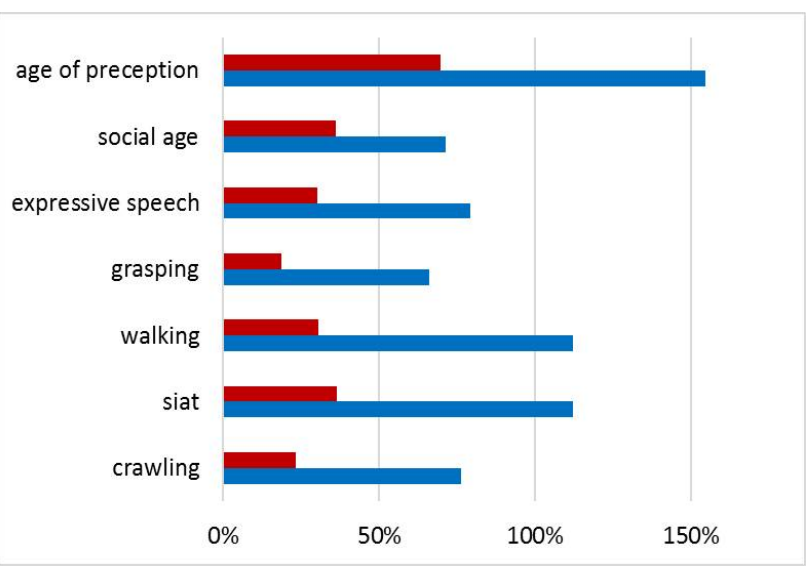

Fig. 1. The ratio of growth of the main indicators of development. Blue shows the results in the 1st group, red - in the 2nd group.

of the 2nd group $(n=53)$ also had encephalopathy of appropriate severity and were registered in the follow-up office (Table 1). The course of early rehabilitation was not carried out for various reasons (mainly due to the parents' refusal to be hospitalized). Both groups of children did not have somatic pathology, which could significantly affect the neurological status. To exclude the influence of additional factors, the main and control groups included children who did not need at the time of the study of drug therapy with drugs that affect the central nervous system. Both groups of children were registered at the dispensary in the followup room of the Vinnytsia Regional Children's Clinical Hospital to monitor the health and psychomotor development of children.

Assessment of psychomotor development on a scale was conducted at the end of the 1st month of life and in 3 full months (Table 2).

In each of the groups there was an improvement in all points of development in a full 3 months. For a more accurate view of the improvement of development in the full 3 months, the increase in the main indicators of development was estimated as a percentage (compared to previous data) (Fig. 1).

\section{Discussion}

According to the results, both groups of children had similar starting positions according to the Munich Functional Diagnosis of Development. After a comprehensive rehabilitation program of Early Intervention in the Department of Neonatal Pathology, the neurological status of children improved in all categories. The most pronounced changes were observed in the motor area (skills of crawling, sitting and walking). Grasping skills, expressive speech and social age were restored at a slower pace. At the same time, the characteristics that assess the age of perception, ie visual and auditory responses, also progressed more intensively. This may be due to the elements of sensory integration that were part of the early rehabilitation complex.

In the group of children who were not able to receive comprehensive treatment immediately after undergoing HIE, basic functions were restored at a slower pace. Moreover, the motor reflex sphere suffered the most. It is likely that the identified differences may be predictors of delays in motor, mental or speech development in old age. Accordingly, it is advisable to monitor children at risk during the first years of life for timely detection of deviations and their correction.

According to a British study [15] on the impact of early development programs on children at high perinatal risk, the greatest effect was exerted by complex programs with an impact on the motor, cognitive and sensory areas. According to the authors, corrective massage and elements of neurodevelopmental therapy (NDT) meet the principles of recurrence and enrichment of the environment around the baby with motor stimuli. In preschool, such children showed better cognitive abilities compared to those who had similar circumstances at birth but did not have access to early rehabilitation. However, excessive sensory stimuli can have a negative effect on behavior at the age of 2 years. According to our observations, in the short run, the motor sphere improves in the first place in comparison with communication skills. While after 2 years of age the differences in motor development between the two groups 
of children are less noticeable. Most likely, with age, the effectiveness of the impact on the motor sphere decreases, which requires further observation. Spittle $A$. and Treyvaud $K$. [25] emphasize the importance of selecting a set of procedures that affect different areas of development. In addition, they point out the importance of education and involvement in the early rehabilitation of the child's parents, as well as the creation of a favorable sensory environment at home. No component of early intervention can be identified as the most effective.

Italian authors used EEG data to assess the effects of newborn massage and obtained improvements in its structure [12]. Their programs for "enrichment of motor space" have shown a positive impact on both motor and mental development in the long run [23].

The authors of a large systematic review of 2016 on early intervention note that the impact on the damaged brain in the neonatal period is required as early as possible due to its high plasticity [14]. They also note the greatest effect of the early intervention system on cognitive development compared to motor in the long run. While our results 3 months after the intervention showed a predominant effect on motor area and perception. Such data may also indicate an inextricable link between the quality of perception and mental development. Which in turn shows the need to include in the rehabilitation system elements of sensory integration. Hadders-Algra M. et al. [14] showed that the isolated use of neurodevelopmental therapy or other author's techniques does not give the desired result. While the combination of different influences improves both the motor and cognitive spheres of the child's development, similar to our results. The authors note that the system of early intervention gives greater prospects to full-term infants who have suffered from encephalopathy. While premature births with periventricular leukomalacia, quite often give a picture of cerebral palsy in old age. The review also emphasizes the importance not only of periodic professional rehabilitation courses, but also of enriching the child's living environment and teaching parents the elements of early intervention. The main conclusions of the authors, analyzing 13 major works in the world at that time on early intervention, are as follows: early intervention affects motor and mental development, the dosage of intervention is crucial and parental involvement in

\section{References}

[1]Aikardi, Z. H., Martin, B., Kristofer, G. Turko, K. S., Gerasimov, A. P., Barashkova, S. V., ... \& Skoromets, A. A. (2013). Заболевания нервной системы у детей [Diseases of the nervous system in children]. М.: Издательство Панфилова; БИНОМ Лаборатория знаний - M.: Panfilov Publishing House; BINOM Knowledge Laboratory.

[2] Badheka, R., Barad, N. K., \& Sankhla, C. S. (2018). Pediatric movement disorders. Neurology India, 66(7), 59-67. doi: 10.4103/0028-3886.226447

[3] Barashnev, lu. І. (1997). Компенсация нарушенных функций ЦНС и значение стимулирующей терапии при перинатальных повреждениях головного мозга новорожденных [Compensation of impaired central nervous system functions and the importance of stimulating therapy in perinatal brain the rehabilitation of the child improves family well-being. Our conclusions on the early effects of the intervention system are quite consistent with those presented and need to be continued in the longer term.

At present, there is no consensus in the world on specific recommendations on the scope and methods of early intervention. But the work carried out to assess various areas of child development after the application of interventions in different countries, like ours, give encouraging results. Most authors are inclined to believe that early intervention should be started as soon as the child's condition allows and selected according to its needs [25]. Existing normative documents in Ukraine on the rehabilitation of children with organic CNS damage apply mainly to those who have already developed neurodevelopmental disorders [20, 22]. Clinical guidelines for infants with a high potential risk of motor, mental or speech developmental disorders need to be developed immediately.

\section{Conclusions}

1. Adverse onset of life, in particular perinatal hypoxicischemic encephalopathies, is one of the factors of poor adaptation in society, high morbidity and low future incomes.

2. The system of early intervention (Earlyinterventionprograms) is generally accepted in the civilized world. Its principles and principles should be implemented in Ukraine for the purpose of social adaptation of children who have suffered perinatal CNS damage.

3. To assess the effectiveness of comprehensive rehabilitation in young children, it is advisable to use adapted for Ukraine scale of Munich functional developmental diagnostics, which allows to assess the child's development in all major areas, its harmony and effectiveness of rehabilitation measures during the first 3 years of life.

4. The development of a national Early Intervention Strategy is relevant and in line with current trends.

5. One of the possible options for solving this problem may be the creation of follow-up departments at children's institutions of the III level of medical care. But their effective functioning is possible under the condition of full-fledged work as centers of early intervention with proper staffing and technical support.

damage in newborns]. Российский вестник перинатологии и педиатрии - Russian Bulletin of Perinatology and Pediatrics, (6), 7-13.

[4] Berezhnyi, V. V. (2013). Педіатрія: національний підручник [Pediatrics: a national textbook]. Київ: б, (2013) - Kyiv: b, (2013).

[5] Busl, K. M., \& Greer, D. M. (2010). Hypoxic-ischemic brain injury: pathophysiology, neuropathology and mechanisms. NeuroRehabilitation, 26(1), 5-13. doi: 10.3233/NRE-2010-0531

[6] Ciuraj, M., Kieszczynska, K., Doroniewicz, I., \& Lipowicz, A. (2019, June). Subjective and Objective Assessment of Developmental Dysfunction in Children Aged 0-3 YearsComparative Study. In International Conference on Information Technologies in Biomedicine (pp. 382-391). Springer, Cham. 
doi: 10.1007/978-3-030-23762-2 34

[7] Clinical Practice Guideline: Report of the Recommendations. (2006). Motor Disorders, Assessment and Intervention for Young Children (Age 0-3 Years). New York State Department of Health, P.O. Box 2000, Albany, New York 12220.

[8] Cowan, F., Rutherford, M., Groenendaal, F., Eken, P., Mercuri, E., Bydder, G. M., ... \& de Vries, L. S. (2003). Origin and timing of brain lesions in term infants with neonatal encephalopathy. The Lancet, 361(9359), 736-742. doi: 10.1016/S01406736(03)12658-X

[9] Detsyk, O. Z., \& Melnyk, R. M. (2017). Вплив появи важкохворої дитини на соціальний статус її родини [The influence of the appearance of a seriously ill child on the social status of her family]. Україна. Здоров'я нації - Ukraine. The health of the nation, (1), 16-21.

[10] Dobrova-Krol, N. (2014). Раннее вмешательство: ключевые аспекты и международный опыт [Early intervention: key aspects and international experience]. URL:http:// www.unicef.org/ukraine/ukr/Early_Intervention_Concept_RUS. pdf (date of the application: 1.05. 2018).

[11] Gajewska, E., Sobieska, M., \& Samborski, W. (2006). Correlates between Munich Functional Development Diagnostics and postural reactivity findings based on seven provovoked postural reactions modus Vojta during the first period of child's life. In Annales Academiae Medicae Stetinensis (Vol. 52, No. 3, pp. 67-70). PMID: 17385350

[12] Guzzetta, A., D'acunto, M. G., Carotenuto, M., Berardi, N., Bancale, A., Biagioni, E., ... \& Cioni, G. (2011). The effects of preterm infant massage on brain electrical activity. Developmental Medicine \& Child Neurology, 53, 46-51. doi: 10.1111/j.14698749.2011.04065.x

[13] Hackworth, N. J., Berthelsen, D., Matthews, J., Westrupp, E. M., Cann, W., Ukoumunne, O. C., ... \& Nicholson, J. M. (2017). Impact of a brief group intervention to enhance parenting and the home learning environment for children aged 6-36 months: A cluster randomised controlled trial. Prevention Science, 18(3), 337-349. doi: 10.1007/s11121-017-0753-9

[14] Hadders-Algra, M., Boxum, A. G., Hielkema, T., \& Hamer, E. G. (2017). Effect of early intervention in infants at very high risk of cerebral palsy: a systematic review. Developmental Medicine \& Child Neurology, 59(3), 246-258. doi: 10.1111/dmcn.13331

[15] Hutchon, B., Gibbs, D., Harniess, P., Jary, S., Crossley, S. L., Moffat, J. V., ... \& Basu, A. P. (2019). Early intervention programmes for infants at high risk of atypical neurodevelopmental outcome. Developmental Medicine \& Child Neurology, 61(12), 1362-1367. doi: 10.1111/dmcn.14187

[16] Johnston, M. V., Fatemi, A., Wilson, M. A., \& Northington, F. (2011). Treatment advances in neonatal neuroprotection and neurointensive care. The Lancet Neurology, 10(4), 372-382. doi: 10.1016/S1474-4422(11)70016-3

[17] Koy, A., Lin, J. P., Sanger, T. D., Marks, W. A., Mink, J. W., \& Timmermann, L. (2016). Advances in management of movement disorders in children. The Lancet Neurology, 15(7), 719-735. doi: 10.1016/S1474-4422(16)00132-0

[18] Landsem, I. P., Handegard, B. H., Ulvund, S. E., Kaaresen, P. I., \& Ronning, J. A. (2015). Early intervention influences positively quality of life as reported by prematurely born children at age nine and their parents; a randomized clinical trial. Health and quality of life outcomes, 13(1), 1-11. doi: 10.1186/s12955-015-
0221-9

[19] Liu, J., Li, J., \& Gu, M. (2007). The correlation between myocardial function and cerebral hemodynamics in term infants with hypoxic-ischemic encephalopathy. Journal of tropical pediatrics, 53(1), 44-48. doi: 10.1093/tropej/fml053

[20] Martyniuk, V. Yu. (2016). Основи соціальної педіатрії. Навчально-методичний посібник: у 2-х $m$ [Fundamentals of social pediatrics. Training manual: in 2 volumes]. К.: ФОП Bepec O.I. - K.: FOP Veres O.I.

[21] Ministry of Health of Ukraine. (2008). Про затвердження Клінічного протоколу медичного догляду за здоровою дитиною віком до 3-х років [On approval of the Clinical Protocol of medical care for a healthy child under 3 years of age]. Нормативно-директивні документи МОЗ України. Наказ № 149 від 20.03.2008 - Regulatory documents of the Ministry of Health of Ukraine. Order № 149 of 20.03.2008.

[22] Ministry of Health of Ukraine. (2013). Прозатвердження клінічних настанов та Уніфікованого клінічного протоколу медичної допомоги та медичної реабілітації "Церебральний параліч та інші органічні ураження головного мозку у дітей, які супроводжуються руховими порушеннями" [About the statement of clinical instructions and the Unified clinical protocol of medical care and medical rehabilitation "Cerebral palsy and other organic defeats of a brain at children which are followed by motor disturbances"]. Нормативно-директивні документи МОЗ України. Наказ № 286 від 09.04.2013 - Regulatory documents of the Ministry of Health of Ukraine. Order № 286 of 09.04.2013.

[23] Morgan, C., Novak, I., Dale, R. C., Guzzetta, A., \& Badawi, N. (2016). Single blind randomised controlled trial of GAME (Goals Activity Motor Enrichment) in infants at high risk of cerebral palsy. Research in Developmental Disabilities, 55, 256-267. doi: 10.1016/j.ridd.2016.04.005

[24] Richter, L. M., Daelmans, B., Lombardi, J., Heymann, J., Boo, F. L., Behrman, J. R., ... \& Lancet Early Childhood Development Series Steering Committee. (2017). Investing in the foundation of sustainable development: pathways to scale up for early childhood development. The Lancet, 389(10064), 103-118. doi: 10.1016/S0140-6736(16)31698-1

[25] Spittle, A., \& Treyvaud, K. (2016). The role of early developmental intervention to influence neurobehavioral outcomes of children born preterm. In Seminars in perinatology (Vol. 40, No 8, pp. 542-548). WB Saunders. doi: 10.1053/j.semperi.2016.09.006

[26] Spittle, A., Orton, J., Anderson, P. J., Boyd, R., \& Doyle, L. W. (2015). Early developmental intervention programmes provided post hospital discharge to prevent motor and cognitive impairment in preterm infants. Cochrane Database of Systematic Reviews, (11), CD005495. doi: 10.1002/14651858.CD005495.pub4

[27] United Nations Office on Drugs and Crime's. (2017). Compilation of Evidence-Based Family Skills Training Programmes. URL: https://www.issup.net/knowledge-share/publications/2017-08/ compilation-evidence-based-family-skills-training-programmes (date of the application: 10.10. 2019).

[28] Voronenko, Yu. V., Hoida, N. H., \& Moiseienko, R. O. (2015). Сучасні аспекти розвитку системи медико-соціальних послуг для уразливих груп дітей в Україні [Modern aspects of the development of the system of medical and social services for vulnerable groups of children in Ukraine]. Український медичний часопис - Ukrainian medical journal, (1), 14-18. 